\title{
Dependence of Research Productivity on Transaction Costs
}

\author{
Evgeny Popov ${ }^{1} \&$ Maxim Vlasov $^{1}$ \\ ${ }^{1}$ Institute of Economics, the Ural Branch of the Russian Academy of Sciences, Yekaterinburg, Russia \\ Correspondence: Maxim Vlasov, Institute of Economics, the Ural Branch of the Russian Academy of Sciences, \\ Yekaterinburg, Moskovskay str. 29, 620014, Russia. Tel: 7-343-371-0067. E-mail: mvlassov@mail.ru
}

Received: October 16, 2012 Accepted: December 3, 2012 Online Published: December 22, 2012

doi:10.5539/ijbm.v8n2p78

URL: http://dx.doi.org/10.5539/ijbm.v8n2p78

\begin{abstract}
The present paper provides an empirical assessment for the dependence of academic organizations' productivity measured quantitatively on the transaction expenses on scientific activity. The establishment of a stable institutional structure is shown to allow the transaction cost minimization, which in turn boosts the publication activity and academic mobility of academic institutions when spent to promote scientific publications and participation of young researchers in conferences.
\end{abstract}

Keywords: knowledge management, economy of knowledge, transaction costs, economic institutions

\section{Introduction}

Rapid advancement of economy based on knowledge has put forward new challenges for the institutional structuring of both creativity and economic activity. Issues of knowledge economy have drawn attention from both foreign and Russian researchers having resulted in a large number of studies. However, modern trends of economics do not offer exhaustive institutional investigations on how transaction costs affect scientific activity.

The present study attempts to provide an empirical assessment for the dependence of academic organizations' productivity measured numerically on the transaction expenses on scientific activity.

\section{Explicit and Implicit Knowledge of Academic Organizations}

To capture the significance of knowledge, Machlup F. (Machlup F., 1962) suggested the following knowledge typology:

1) practical knowledge;

2) intellectual knowledge;

3) everyday and entertaining knowledge;

4) spiritual knowledge;

5) unnecessary knowledge.

Developing this typology, Machlup F. focused on the possibilities of using the knowledge in different spheres of economy. Given the economic activity only makes use of the formalized knowledge, the typology considers a particular part of knowledge, namely, the explicit one. Though paying attention to the nonformalized, existing only in hypothesis, knowledge neither Machlup F., nor Scheler M. (Scheler M., 1980) included it in the typology.

It was Nonaka I. and Takeuchi H. who were the first to suggest considering types of knowledge according to the extent of formality. All new pieces of knowledge were divided into the explicit and implicit ones (Nonaka I., Takeuchi H., 1994).

In the frames of the present investigation we offer to use the following definitions. Implicit knowledge is the personality's non-formalized knowledge; it takes extra theoretic or methodological treatment. Explicit knowledge is impersonal formalized knowledge being distributed.

For the sake of this study we developed a number of indicators for knowledge gain of both explicit and implicit types (Fig.1). Among the indicators of explicit knowledge we singled out: the number of monographs and articles published in Russian and foreign scientific papers, the number of patents acquired and filled, as well as the number of exhibitions attended. In such a way the general public is believed to get the formalized scientific ideas, applied technologies, etc. 
The indicators of implicit knowledge cover the conference reports, the number of conference abstracts published (both Russian and abroad conferences), as well as the number of symposiums, conferences and schools held. The conferences and symposiums are assumed to discuss the ideas, which have not found recognition yet and need to be completed. So, this knowledge can be referred to as the implicit one.

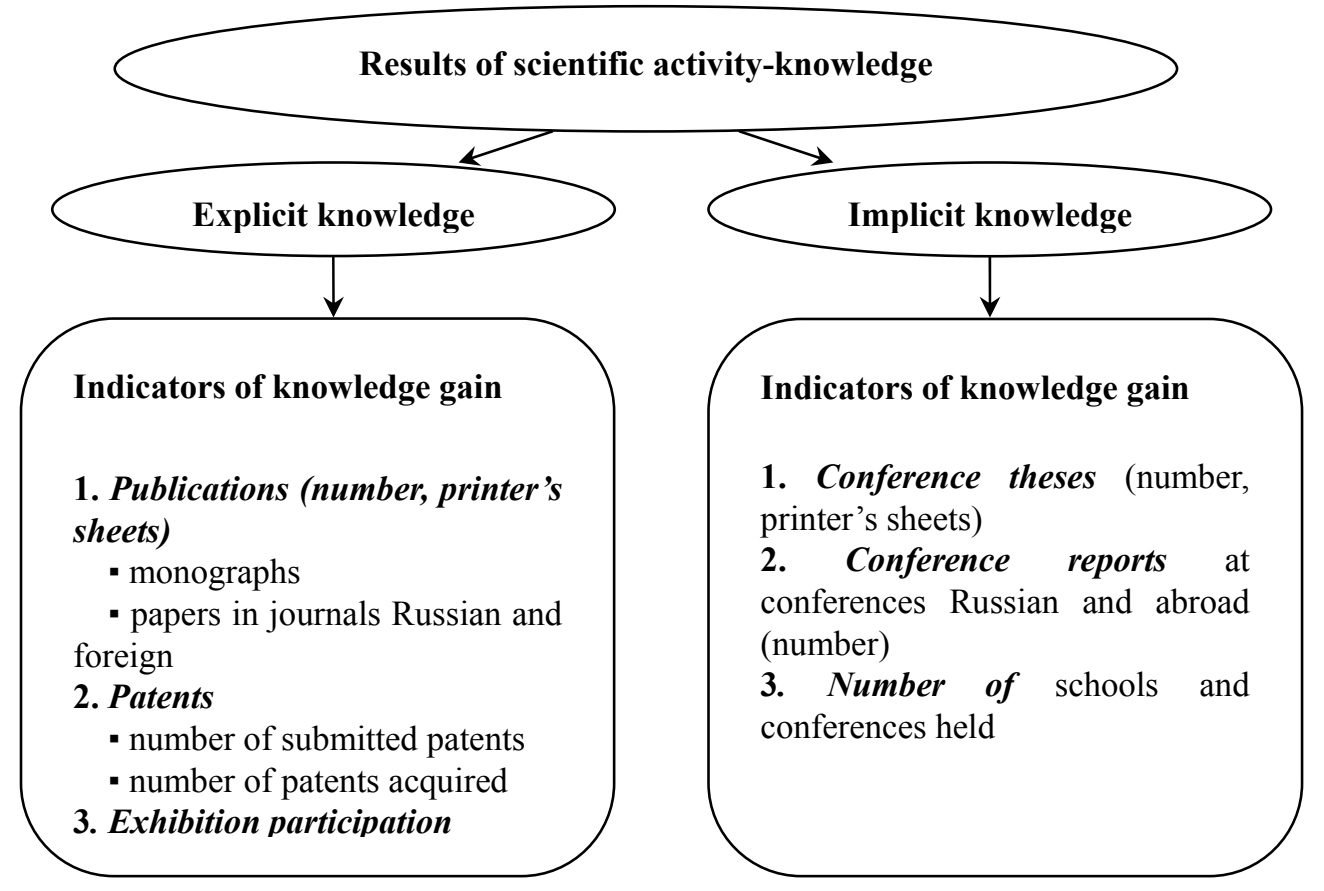

Figure 1. Indicators of knowledge gain in academic organization

Efficiency indices of research productivity are affected by myriads of factors: both the internal factors of development (scientific, technical, material, financial ones); and external factors (law, economy, society and others).

The size and structure of transaction costs in an academic organization take a special place among the internal factors. However, the investigations on the institutional knowledge description show an obvious lack of understanding as to how transaction costs influence the generation of new knowledge by academic organizations.

\section{Transactional Dimension of Academic Organizations' Activity}

Despite the fact that the term 'transaction' traces its history back to over 80 years ago since the famous work of Commons J. (Commons J., 1931), the nature and kinds of transactions have not been shed enough light on yet. Obviously, the economic theoreticians find it much easier to handle the categories of higher rank such as 'transaction costs' and 'economic institutions' due to their quantative and qualitative certainty. However, transactions remain the initial element for the analysis of institutional economy, with the understanding of their nature and kinds forming a solid ground for modern economic models.

If by economic agents we imply the subjects of economic relations taking part in production, distribution, exchange and consumption of economic benefits, then the meta-production relations between them are determined by the processes of ownership transfer and activity restriction.

The most large-scale definition of transaction was offered by a Nobel prize-winner Williamson O. in 2009: 'transaction occurs when a good or service is transferred across a technogically separable interface; the end of one production stage and the beginning of another.' (Williamson O., 1991)

Giving a brief summary, by transaction we understand the process of ownership transfer or activity restriction between economic agents.

The concept of transaction costs was first introduced by R. Coase in the 30 s of the last century in his article 'The Nature of a Firm'. It was used to provide an insight on the existence of such a hierarchical structure as a firm, being oppositional to a market. R. Coase explained the emergence of these 'islands of consciousness' with their respective advantages in terms of transaction cost minimization. Specificity of a firm functioning he thought to 
be brought about by the suppression of a price mechanism and its substitution with the inner administrative control (Coarse R., 1937).

In the framework of contemporary economic theory transaction costs have gained a variety of treatments.

K. Arrow approaches transaction costs as the costs of economic system exploitation. He compared the influence of transaction costs on economy with the one of friction in physics. Such suggestions triggered conclusions that the closer the economy comes to the Walras's general equilibrium model the lower the level of transaction costs it demonstrates, with the opposite being as true (Arrow K., 1994).

D. North determined transaction costs as consisting of 'the costs of assessment the useful properties of exchange goods and the costs of property rights security and enforcement on their execution' (North D., 1981). These costs he believed to be the source of social, economic and political institutions.

Taking the notions of Arrow K. and North D. for granted, we take the value estimation of economic institution to be the transaction costs of establishing the norm of interaction between economic agents.

To sum up, from the perspective of academic scientific activity the transaction costs include the nonproductive expenses of participating in scientific conferences, as well as of preparing the scientific papers for publication, with the costs of generating new knowledge by scientists being considered as the productive costs.

\section{Procedure of Empirical Study}

The choice of transaction costs estimation in terms of the research productivity analysis has been stipulated by the different nonproductive financing of scientific organizations along with their equal budgetary funding based on the staff number. In such a case, the assessment of transaction costs allows to comprehend the publication activity potential and the scientific mobility of academic organizations.

In the previous studies, the authors singled out two patterns of academic institutions' transaction costs. In an academic sector of science, lion's share of transaction costs of knowledge gain proved to be of two kinds - the costs of information search and research publication, as well as those of negotiations (Popov E., Vlasov M., 2011).

The costs of information search are the costs of information exchange with outer and inner environment of an organization, as well as the costs of information monitoring.

The costs of negotiations are the costs of preparing and signing the contract, including the costs of communication, strategic costs (such as entertainment expenses) for production firms. For academic organizations the negotiation costs embrace the transport and travel costs, as well as the conference fees.

To obtain the compatible results, we have selected four organizations of the same science profile and one social science profile institution of the Ural Branch of the Russian Academy of Sciences as representative sampling.

Having received the agreement from the heads of these scientific institutions, we filed the accounting reports, the data on publication activity and scientific mobility in the period of 2005-2009. Treating this information yielded the empirical dependences of the change in the number of publications and conference research reports on the change in transaction costs. The preliminary discussion of the empirical study results made obvious some distinct correlations between the publication dynamics and conference reports and the change in transaction costs in every single organization under study.

Given the initial hypothesis of the significant impact the age structure in an organization has on the research productivity of academic institutions, we assigned the ordinal number to the peer science profile organizations due to the increase in the number of mature researchers' share (Table 1).

The analysis of the Table 1 revealed two interesting facts. First of all, the science profile organizations under study are characterized by a substantial age gap: the number of most active researchers in the age of 40 to 49 is no more than $13 \%$. It seems to be most likely due to some researchers having moved to the real economy sector in the 90s of the last century. Secondly, this generation gap is a little less critical in the institutions of social science profile: the share of 40 year old researchers is over $16 \%$. We can predict an increase in the share of researchers for the humanity and social discipline organizations in the 2000 s. 
Table 1. Distribution of academic organizations under study due to the share of mature (over 50 year-old) and young (up to 39 year-old) researchers

\begin{tabular}{lcc}
\hline Conventional name of organization & Share of mature researchers, \% & Share of young researchers, $\%$ \\
\hline First organization & 0.35 & 0.54 \\
First organization & 0.59 & 0.28 \\
Third organization & 0.63 & 0.29 \\
Forth organization & 0.73 & 0.14 \\
Social science organization & 0.50 & 0.33 \\
\hline
\end{tabular}

The results obtained facilitate the understanding of how transaction costs affect research productivity. It is of great interest to compare the dynamics of publication activity with that of the similar academic organizations.

Fig. 2, 3 illustrate the empirical results of the publication activity and scientific mobility dynamics on the change in transaction costs for the academic organizations studied.

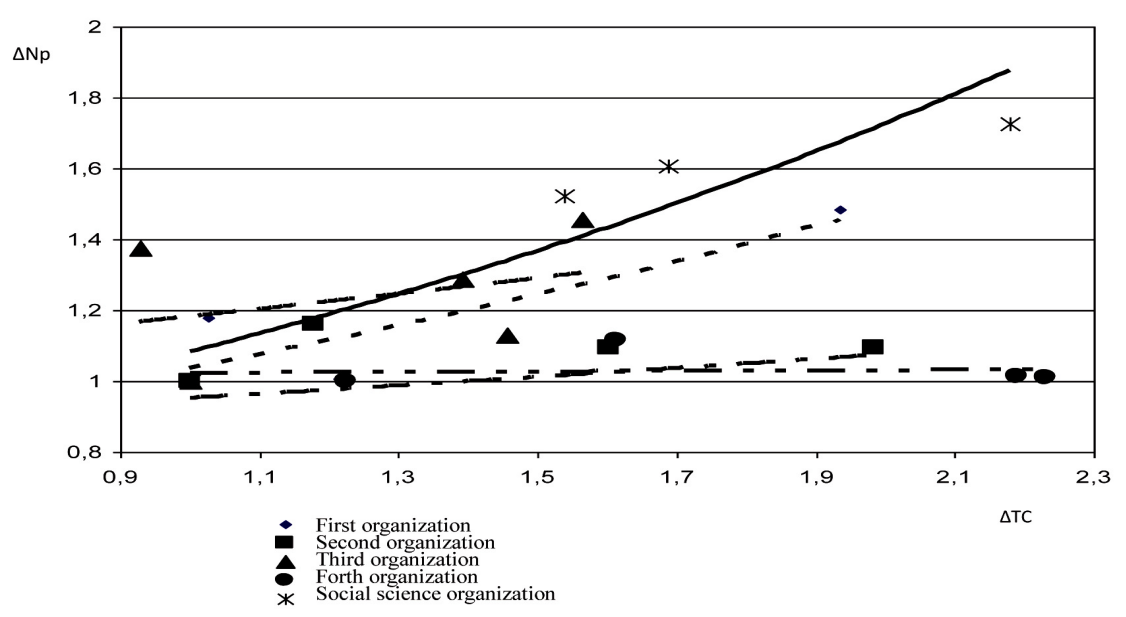

Figure 2. Dynamics of the number of articles published on the transaction costs change in the organizations studied

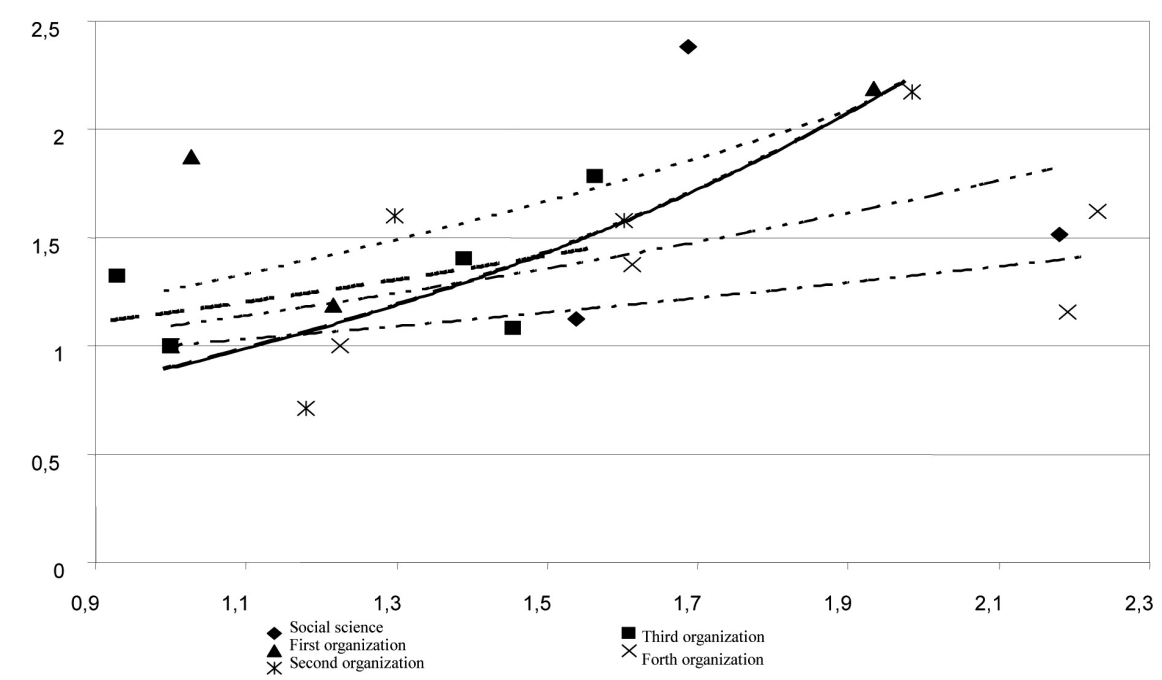

Figure 3. Dynamics of the number of conference reports on the transaction cost change in the organizations studied 
It is worth mentioning that these econometric dependencies were obtained not only for the overall number of publications and conference reports, but for the same values according to the Russian and world magazines and conferences, respectively.

\section{Publication Activity}

Let us turn to the dynamics of publication activity in the academic organizations under consideration. By publication activity we mean the empirically determined exponential dependences of the change in the published article volume (measured in printer's sheet) on the change in organization's transaction costs.

Table 2 illustrates the indicators of exponents for the empirical dependences obtained. The exponent indicators of the total publication activity dynamics on the transaction costs are seen to be in inverse proportion to mature researchers' shares in the given research organizations. Undoubtedly, the increase in the share of young researchers in the RAS institutions can not but stimulates creativity which is reflected in the publication of scientific papers.

Table 2. Exponent indicators of publication activity dynamics (in printer's sheets) on the change in transaction costs

\begin{tabular}{lccc}
\hline \multirow{2}{*}{ Conventional name of organization } & \multicolumn{3}{c}{ Exponent indicators } \\
\cline { 2 - 4 } & Total number of articles Articles in Russian papers Articles in foreign papers \\
\hline First organization & 0.36 & 0.46 & 0.13 \\
Second organization & 0.17 & 0.08 & 0.29 \\
Third organization & 0.12 & -0.06 & 0.52 \\
Forth organization & 0.01 & -0.06 & 0.17 \\
Social science organization & 0.47 & 0.46 & 0.01 \\
\hline
\end{tabular}

The results of empirical study demonstrate the increase in $1 \%$ of young researchers' share to bring about the $1 \%$ growth of the publication activity, with the comparison between the first and the forth organizations being done through rounding up to the first significant digit. This, in turn, means the growth of the exponent in $7 \%$, being proportional to the number of research publications.

For the sake of comparison, the table gives the results obtained for the social science profile organization. As it was expected, the dynamics of article publication dependent on the transactional costs bears here high indices. The matter of the fact is that the number of articles published is the major indicator of productivity for the researchers in social sciences and humanities. These researchers can not report on their achievements with patents and discoveries as scientists do. Another specific feature for the organizations of social science profile is the predominance of having the papers published in Russian magazines.

The overall result of young researchers' effect on the research productivity is also proved when the publication activity is measured in the number of articles published instead of assessing it in publication volume.

Another significant issue deemed important for the analysis is comparing the publication activity separately for Russian and foreign scientific journals. Here, the situation seems ambiguous. Even in this case, the share of young researchers in the organizations studied is directly proportional to the research activity dynamics when the articles are published in Russian journals. However, as far as publications in foreign journals are concerned, this dynamics correlates with the share of mature researchers in the organizations.

The dependence of the outside right column in the Table 2 can be explained by introducing the rating system of assessing the research productivity in the course of reforming the RAS in 2007-2009 (this period covers the database of the present study). According to the rating estimates suggested, publications in foreign papers have higher rank than publications in the Russian ones. Hence, there is a tendency for mature researchers to have their articles published in foreign papers and, as a result, to get higher grade.

To draw an intermediate line at the analysis of the publication activity for peer science organizations, the increase in the share of young researchers in an organization is proved to be a solid ground for a distinct growth in the dynamics of academic organizations' publication activity. 


\section{Academic Mobility}

We carried out the similar analysis of academic mobility. By this phenomenon we understand the empirically determined exponential dependences of the change in the conference reports on the change in organization's transaction costs. Table 3 gives the indicators of exponents for the empirical dependences obtained.

The dependences involved do not have a pronounced correlation between the young researchers' share and academic mobility. Nevertheless, we succeeded in acquiring some tendencies.

Table 3 demonstrates that along with the decrease in the share of young researchers from the second to the forth organization, there is a decrease in the academic mobility dynamics dependent on the change in organization's transaction costs. Eventually, the $1 \%$ increase in the share of young researchers may bring about the $5 \%$ growth in academic mobility, with the comparison between the second and the forth organizations being done through rounding up to the first significant digit.

Table 3. Exponent indicators of academic mobility dynamics (in the number of conference reports) on the change in transaction costs

\begin{tabular}{lccc}
\hline Conventional name of organization & \multicolumn{3}{c}{ Exponent indicators } \\
\cline { 2 - 4 } & $\begin{array}{c}\text { Total number of } \\
\text { conference reports }\end{array}$ & $\begin{array}{c}\text { Reports in Russian } \\
\text { papers }\end{array}$ & $\begin{array}{c}\text { Reports in foreign } \\
\text { papers }\end{array}$ \\
\hline First organization & 0.56 & 0.31 & 2.67 \\
Second organization & 0.92 & 0.95 & 0.57 \\
Third organization & 0.40 & 1.12 & -0.07 \\
Forth organization & 0.28 & 0.26 & 0.30 \\
Social science organization & 0.43 & - & - \\
\hline
\end{tabular}

Thus, the $1 \%$ increase in the share of young researchers with the $1 \%$ increase in the transaction costs may raise the academic mobility by $36 \%$. This is certainly the maximum estimate taken from the comparison between the second and the forth organization, however, it allows to assess the effect of young researchers on the conference participation.

In other words, the increase in young researchers' share makes a solid ground for boosting the academic mobility with a rise in transactional costs related, first of all, to travel expenses and conference fees.

A relatively low rate for the social science profile organization proves the fact that the academic mobility dynamics supported by transaction costs has fairly similar conditions independently on the organization profile.

Nevertheless, Table 3 shows the rate of academic mobility in Russian conferences to rise with the increase in the share of mature researchers (from the first to the third organization). We are bound to explain this by the traditions and experience of mature researchers to participate in conferences. It also shows a broad range of possibilities of such participation for Academy's mature researchers.

\section{Conclusion}

The present study carried out with the purpose of empirical assessment for the dependences of the academic productivity measured numerically on the transaction costs on scientific activity allowed the following theoretical and practical results.

Firstly, an increase in young researchers' number along with a little rise in the transaction costs of information search results in the jump in publication activity of scientific organizations, with the share of young researchers in the institutions studied being directly related to the scientific activity dynamics when the articles are published in Russian academic journals. When the research results are published in foreign papers, the number of articles published is directly proportional to the number of mature researchers in these academic institutions.

Secondly, an increase in the number of young researchers, though making up a solid basis for the scientific mobility enhancement, entails extra transaction costs related both to the travel expenses and the conference fees. However, the dynamics of scientific mobility in Russian conferences rises with an increase in the share of mature researchers.

Thirdly, an increase in the number of young researchers along with the related low rise in the transaction costs 
involves abrupt growth in the participation of Russian researchers in foreign scientific conferences. In other words, the dynamics of overseas scientific mobility is largely determined by the participation of young researchers in symposiums, setting and conferences.

Fourthly, according to the author's model of transactional function, a decrease in the transaction costs of publication activity is likely to take place if a list of academic journals, as well as the stable submission requirements, are settled.

Fifthly, building a settled schedule for the scientific conferences and the conference requirements may as well cause a reduction in the transaction costs of scientific mobility.

Consequently, forming a stable institutional structure for the academic journals and conferences allows the transaction costs minimization, which in turn may bolster the publication activity and the scientific mobility of academic institutions when spent to ensure scientific publications and participation of young researchers in conferences.

\section{Acknowledgment}

This Research has been performed due to the RAS Program № 35 'Economics and Sociology of Science and Education', project № 12-P-7-1006 'Regional Institutions of Science Development'.

\section{References}

Alvarez F., \& Veracierto M. (1999). Labor-Market Policies in an Equilibrium Seach Model. NBER Macroeconomics Annual, 14, 265-304.

Arrow, K. J. (1994). Methodological Individualism and Social Knowledge. American Economic Review, 84(2), $1-9$.

Benassy J. P. (1986). On Competitive Market Mechanisms. Econometrica, 54(1), 95-108. http://dx.doi.org/10.2307/1914159

Bjørnåli E. S., \& Gulbrandsen M. (2010). Exploring board formation and evolution of board composition in academic spin-offs. The Journal of Technology Transfer, 35(1), 92-112. http://dx.doi.org/10.1007/s10961-009-9115-5

Coase R. H. (1937). The Nature of Firm. Economica, New Series, 4(16), 386-405. http://dx.doi.org/10.1111/j.1468-0335.1937.tb00002.x

Cunha A. B. (2007). The Optimality of the Friedman Rule when Some Distorting Taxes are Exogenous. Economic Theory, 28(4), 179-205.

Globerman S., Roehl Th. W., \& Standifird S. (2001). Globalization and Electronic Commerce: Inferences from Retail Brokering. Journal of International Business Studies, 32(4), 749-768. http://dx.doi.org/10.1057/palgrave.jibs.8490993

Heinesen E. (1995). The Two-Variable CES Transaction Function in Macroeconomic Rationing Models. Econ. Letters, 48(3-4), 257-265. http://dx.doi.org/10.1016/0165-1765(94)00630-K

John R. Commons. (1931). Institutional Economics. American Economic Review, 21(4), 652.

Kolstad Ch. D., \& Turnovsky M. H. L. (1998). Cost Functions and Nonlinear Prices: Estimating a Technology with Qulity-Differentiated Inputs. The Review of Economics and Statistics, 80(3), 444-453. http://dx.doi.org/10.1162/003465398557546

Machlup F. (1962). The Production of Information and Knowledge. Princeton, NJ: Princeton University Press.

Matthews R. C. O. (1986). The Economics of Institutions and Sources of Growth. Economic Journal, 96(12), 903-910. http://dx.doi.org/10.2307/2233164

Nilsson A. S., Rikne A., \& Bengtsson L. (2010). Transfer of academic research: uncovering the grey zone. The Journal of Technology Transfer, 35(6), 617-636. http://dx.doi.org/10.1007/s10961-009-9124-4

Nonaka I., \& Takeuchi H. (1994). The Knowledge-Creating Company: How Japanese Companies Create the Dynamics of Innovation (p. 284). Oxford University Press.

North D. (1981). Strukture and Change in Economic History. N.Y.: Norton.

North D. C., \& Thomas R. P. (1973). The Risk of the West World: a New Economic History. Cambridge: Cambridge University Press. http://dx.doi.org/10.1017/CBO9780511819438 
Ostrom E. (2008). Institutions and the Environment. Economic Affairs, 28(3), 24-31. http://dx.doi.org/10.1111/j.1468-0270.2008.00840.x

Popov E. V. (2008). Transaction Function. International Advances in Economic Research, 14(4), 475-476. http://dx.doi.org/10.1007/s11294-008-9185-4

Popov E. V., \& Vlasov M. V. (2008). Institutional Analysis for Economy of Knowledge. Economy \& Business, 2(1), 1116-1126.

Popov E. V., \& Vlasov M. V. (2011). Resource Differentiation of Knowledge. iBusiness, 3(2), 211-217. http://dx.doi.org/10.4236/ib.2011.32028

Popov E. V., \& Vlasov M. V. (2011). Veretennikova A.Y. Institutional Matrix of Knowledge Generation. Proceedings of the 12th European conference on knowledge management (pp. 780-788).

Popov E. V., Vlasov M. V., \& Zubareva M. O. (2011). Developing Institutions of Knowledge Economy. Proceedings of the 12th European conference on knowledge management (pp. 789-800).

Rahardjo E., Mirchandani D., \& Joshi K. (2007). E-Government Functionality and Website Features: A Case Study of Indonesia. Journal of Global Information Technology Management, 10(1), 31-50.

Scheler M. (1980). Problems of a Sociology of Knowledge. London: Routledge \& Kegan Paul.

Shumpeter J. A. (1952). The Theory of Economics Development. London: George Alien \& Unwin.

Sorensen J. A. T., \& Chambers D. A. (2007). Evaluating academic technology transfer performance by how well access to knowledge is facilitated-defining an access metric. The Journal of Technology Transfer, 33(5), 534-547. http://dx.doi.org/10.1007/s10961-007-9038-y

Veblen T. (1898). Why is Economic not an Evolutionary Science. Quarterly Journal of Economics, 12(4), 373-397. http://dx.doi.org/10.2307/1882952

Veblen T. (1919). The Place of Science in Modern Civilization and Other Essays (P. 239). N.Y.: Huebsch.

Visser Evert J. (2007). Logistic innovation in global supply chains: an empirical test of dynamic transaction-cost theory. GeoJournal, 70(2-3), 213-226. http://dx.doi.org/10.1007/s10708-008-9133-0

Vuchelen J., \& Hove L. V. (2002). An Early Evaluation of the Introduction 0f Euro Banknotes and Coins. Journal of Economic studies, 29(6), 370-387. http://dx.doi.org/10.1108/01443580210448835

Williamson O. E. (1979). Transaction-Cost Economics: the Governance of Contractual Relations. Journal of Low and economics, 22(2). http://dx.doi.org/10.1086/466942

Williamson O. E. (1991). Strategizing, Economizing and Economic Organization. Strategic Management Journal, 12, 75-94. http://dx.doi.org/10.1002/smj.4250121007

Zinkhan G. M. (2004). Accessing Academic Research through an E-Database: Issues of Journal Quality and Knowledge Use. Journal of the Academy of Marketing Science, 32(4), 369-370. http://dx.doi.org/10.1177/0092070304267963 